\title{
Defect reconstruction of the trochanter major after necrotizing fasciitis and multiple operations using an arteriovenous loop and latissimus dorsi free flap
}

\author{
Andreas Arkudas', Susanne Regus ${ }^{2}$, Alexander Meyer ${ }^{2}$, Werner Lang ${ }^{2}$, Marweh Schmitz', Raymund E. \\ Horch $^{1}$

\begin{abstract}
'Department of Plastic and Hand Surgery, University Hospital of Erlangen, Friedrich-Alexander-University of Erlangen-Nürnberg (FAU), Erlangen 91054, Germany.

${ }^{2}$ Department of Vascular Surgery, University Hospital of Erlangen, Friedrich-Alexander-University of Erlangen-Nürnberg (FAU), Erlangen
\end{abstract} \\ 91054, Germany.
}

\begin{abstract}
Correspondence to: Dr. Andreas Arkudas, Department of Plastic and Hand Surgery, University Hospital of Erlangen, FriedrichAlexander-University of Erlangen-Nürnberg (FAU), Erlangen 91054, Germany. E-mail: andreas.arkudas@uk-erlangen.de
\end{abstract}

\begin{abstract}
How to cite this article: Arkudas A, Regus S, Meyer A, Lang W, Schmitz M, Horch RE. Defect reconstruction of the trochanter major after necrotizing fasciitis and multiple operations using an arteriovenous loop and latissimus dorsi free flap. Plast Aesthet Res2018;5:38. http://dx.doi.org/10.20517/2347-9264.2018.44
\end{abstract}

Received: 10 Jun 2018 First Decision: 15 Aug 2018 Revised: 22 Aug 2018 Accepted: 22 Aug 2018 Published: 28 Sep 2018

Science Editor: Raymund Engelbert Horch Copy Editor: Yuan-Li Wang Production Editor: Zhong-Yu Guo

\begin{abstract}
Necrotizing fasciitis (NF) is a severe soft tissue infection which has to be treated with a radical debridement as the key element. In the further course often large tissue defects occur, so that a long-term stable defect reconstruction plays a crucial role after any successful debridement. The reconstruction can include split skin grafting or local and free flaps. Here we present a case of a 41-year-old male patient with a NF in the trochanter major region after spondylodesis and spinal cord stimulation (SCS) device implantation. After multiple operations including local and free flaps we performed a defect reconstruction using an arteriovenous (AV) loop and subsequent free latissimus dorsi transplantation leading to no further operations. This complex reconstruction can be considered as the final stage of any reconstruction latter.
\end{abstract}

Keywords: Necrotizing fasciitis, arteriovenous loop, free latissimus dorsi flap transplantation

\section{INTRODUCTION}

Necrotizing fasciitis (NF) is a rare and severe infection caused by different kinds of bacteria ${ }^{[1,2]}$. The first and most important therapy is a radical debridement of all infected tissue leading to large soft tissue defects. Mostly, these tissue defects can be reconstructed using split skin grafts, but in areas of joints or when other structures like bone, vessels or nerves are exposed, defect coverage using local or free flaps is required. In the

\footnotetext{
().

(C) The Author(s) 2018. Open Access This article is licensed under a Creative Commons Attribution 4.0 International License (https://creativecommons.org/licenses/by/4.0/), which permits unrestricted use, sharing, adaptation, distribution and reproduction in any medium or format, for any purpose, even commercially, as long as you give appropriate credit to the original author(s) and the source, provide a link to the Creative Commons license, and indicate if changes were made.
}

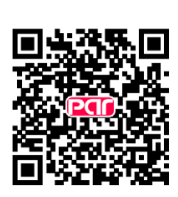



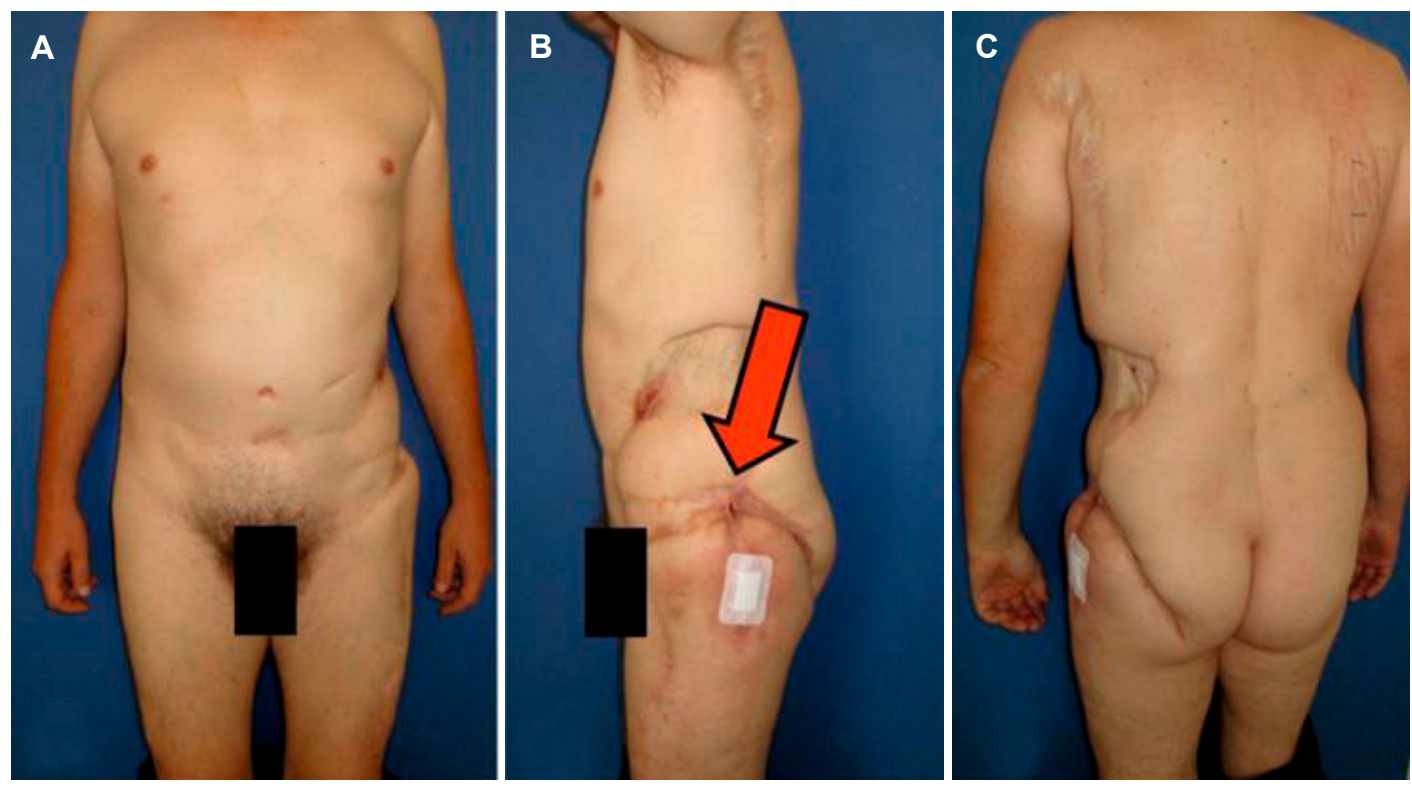

Figure 1. Forty-one-year-old male patient with an unstable scar and fistula in the trochanter major region (arrow)

groin and hip region local random pattern flaps such as rotational flaps can be used. Also pedicled flaps such as the anterior lateral thigh (ALT) flap or vertical rectus abdominis myocutaneous (VRAM) flap can achieve stable healing of these defects ${ }^{[3-5]}$. When local flaps are not available due to previous operations or did not lead to the required result, free flaps are the last therapeutical option. Free flaps are raised at a distant body part also known as donor site and are microsurgically anastomosed to recipient vessels at the defect area ${ }^{[6]}$. Typical free flaps are the latissimus dorsi flap, the parascapular flap or perforator flaps such as the deep inferior epigastric perforator (DIEP) or the ALT flap. When local recipient vessels are missing, e.g., in cases of trauma or infection, an arteriovenous (AV) loop from a main vascular axis can be used to enable local microsurgical anastomoses for free flap transfer ${ }^{[7,8]}$.

Here we present a patient with NF and multiple operations including local and free flaps who was referred to our hospital with ongoing fistulas in the trochanter major region. After radical debridement defect coverage was achieved using an arteriovenous loop with subsequent free latissimus dorsi flap transplantation.

\section{CASE REPORT}

A 41-year-old male patient suffered from back pain since he was 16 years old. He received multiple treatments including a spondylodesis of L4 and L5 using an anterior approach. In the further course the patient developed a wound dehiscence of the abdominal incision which was treated conservatively. Also the spondylodesis was extended to S1. Due to persistent back pain a spinal cord stimulation (SCS) device was implanted leading to a NF of the left flank. Therefore the SCS devise was explanted and in the further course a split skin graft transplantation of the left flank was performed. Also a rotational flap was made in the left groin. Due to an unstable scar in the left iliac crest region defect coverage was attempted using a groin flap. Afterwards again a NF occurred in the left hip region resulting in multiple fistulas after several debridements. In the further course a pedicled DIEP flap was attempted and a free parascapular flap anastomosed to the circumflexa iliaca profunda vessels and a pedicled ALT flap were performed in order to achieve a stable healing of this region.

Unfortunately, the patient still suffered from an ongoing fistula and an unstable scar in the left trochanter 

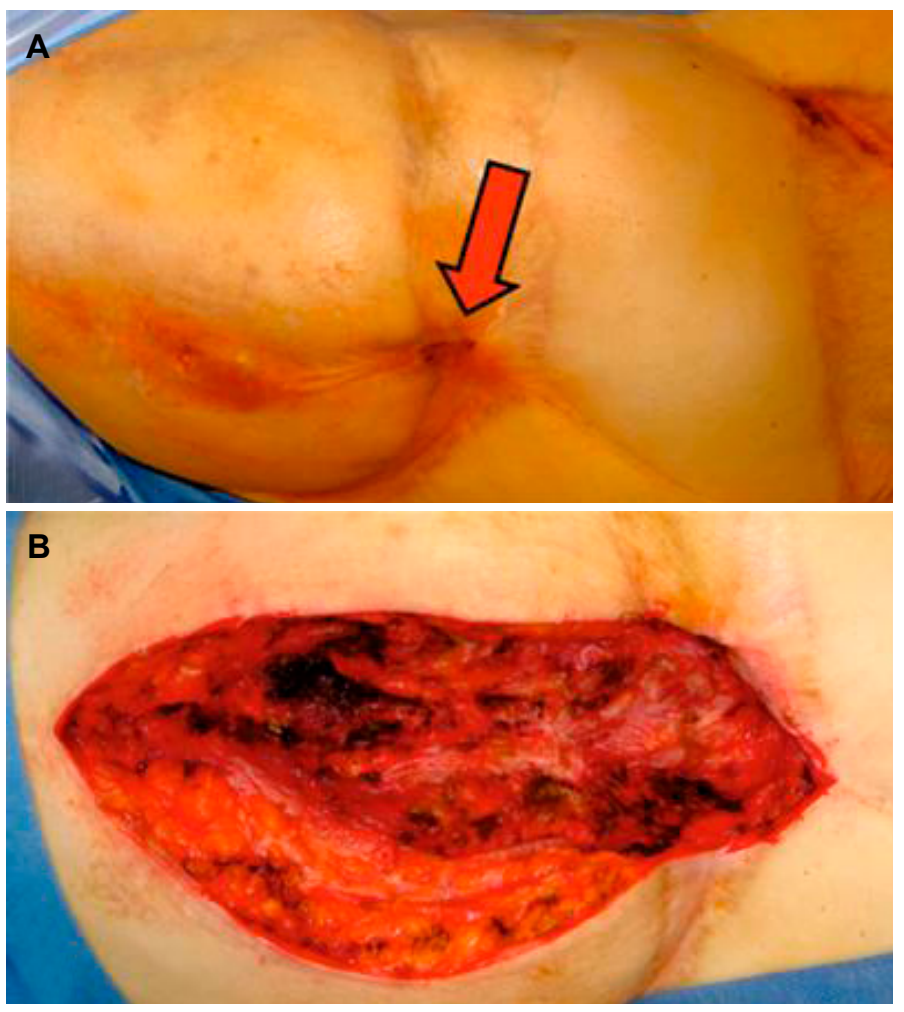

Figure 2. Before $(A)$ and after $(B)$ radical debridement of the scar tissue in the trochanter major region

major region and was therefore referred to our hospital [Figure 1]. An magnetic resonance imaging (MRI) examination of the left thigh revealed a fistulating process in subcutaneous region of the left upper thigh extending down to the gluteus maximus muscle. Also, bacteria culture of wound exudates showed a staphylococcus aureus contamination. We performed several debridements of the scar tissue and the fistula down to the trochanter major and intermittent negative pressure wound therapy (NPWT) [Figure 2]. Histological examination revealed a chronic granulating and ulcerating soft tissue infection without proof of an osteomyelitis. In a two-step procedure, defect reconstruction was achieved using a free latissimus dorsi flap [Figure 3]. Due to missing recipient vessels in the defect area, AV loop was created from the left femoral vessels using a saphenous vein graft in the first step. Postoperatively patency of the AV loop was checked using Doppler ultrasound. After four days a free myocutaneous latissimus dorsi flap was microsurgically anastomosed to the AV loop. Therefore the AV loop was cut into two legs, and the arterial anastomosis of the subclavian artery and the arterial AV loop leg was performed under microscope magnification using 8-0 suture material. The venous anastomosis of the subclavian vein and the venous AV loop leg was performed using a $4.0 \mathrm{~mm}$ coupler device. The latissimus dorsi muscle was used to seal the tissue defect down to the trochanter major whereas the skin island was inserted to close the skin defect without the requirement of a split skin graft. Postoperatively flap perfusion was checked using capillary refill of the skin island and Doppler ultrasound. The flap was adequately perfused at all times and no revision war necessary. Mobilization of the patient was performed using a dangling regime. Cefuroxim was administered intravenously during the hospital stay and afterwards in oral form for a total of six weeks postoperatively. Due to a postoperative anemia the patient received two red cell concentrates in the further course. The patient was discharged from the clinic 13 days after free flap transplantation. In the further course a wound healing disorder occurred in the ventral part of the skin island. MRI examination of the pelvic showed no recurrent fistula, whereas a subcutaneous infection could be observed leading to no further operative intervention. 

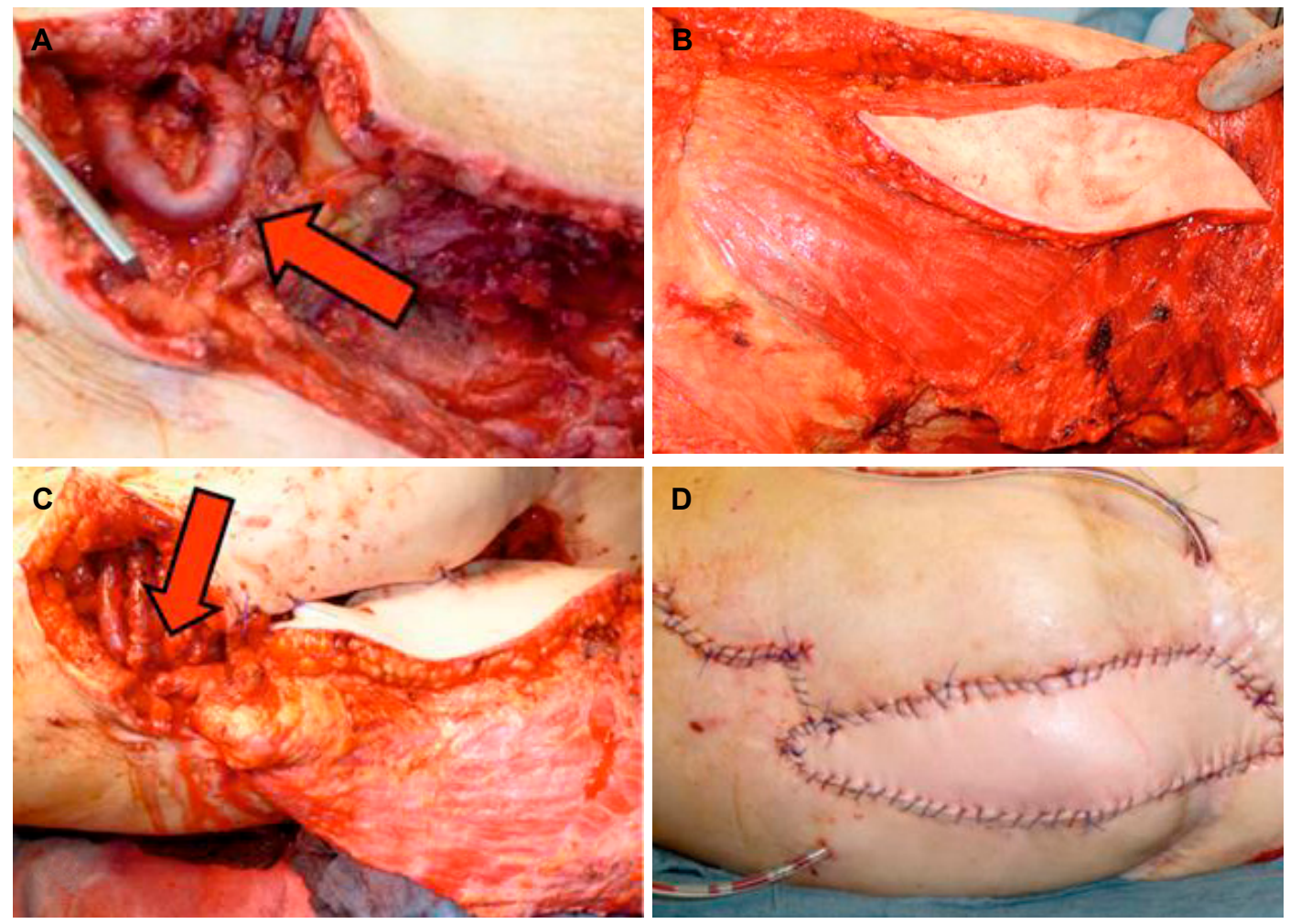

Figure 3. An arteriovenous loop ( $A$, arrow) was created in the left upper thigh using a greater saphenous graft. Afterwards, a latissimus drosi flap was raised (B) and microsurgically anastomosed to the AV loop legs (C, arrow). Result at the end of the operation with a well perfused latissimus dorsi skin island without signs of arterial or venous congestion (D). AV: arteriovenous

\section{DISCUSSION}

NF can be caused by small skin lesions and is predominantly spread along the deep fascia. There are different kinds of bacteria known to be responsible for these massive infections such as beta-hemolytic group A streptococci, anaerobes or clostridium and fungal species ${ }^{[9]}$. In the presented case the staphylococcus aureus was proven to be causally responsible for the ongoing fistula and subacute infections. The bacterium was first documented in the abdominal wound dehiscence after the first spondylodesis operation. After implantation of the SCS device an abdominal NF had occurred as a device-related infection ${ }^{[10]}$. Due to the bacterial biofilm on the SCS device, one important part of healing such infections is the explantation of any alloplastic material. The radical debridement is the key element of any successful NF treatment. Even when the patients are treated correctly, the mortality rate amounts up to $15 \%-46 \%{ }^{[9]}$. Without adequate treatment the mortality rate raises up to nearly $100 \%$. Afterwards a split skin grafting was performed in the groin/hip region. Due to its unstable reconstruction a local flap was performed. Basically, there are two different types of flaps regarding their vascularization: flaps perfused by a random pattern vascular pathway, also known as the extrinsic vascularization, and flaps, which rely on a vascular axis, so called intrinsically perfused flaps ${ }^{[1,12]}$. Furthermore, intrinsically perfused flaps can be transferred as pedicled flaps into the defect or can be transplanted using microsurgical techniques as free flaps to distant parts of the body ${ }^{[3,13]}$. Based on the reconstruction latter, in this case a rotational random pattern flap was performed first to reconstruct the lateral defect in the groin/hip area. Afterwards local pedicled flaps were used to achieve a stable wound healing. Therefore a pedicled groin flap and the attempt of a DIEP flap were performed. As a next step, a free parascapular flap was microsurgically anastomosed to the circumflexa iliaca profunda vessels in order to reconstruct the defect in the trochanter major region. Due to its ongoing fistulas also a pedicled ALT flap was transferred to this region. At this stage the patient was referred to our hospital. There were no local flaps 
available, neither random pattern nor pedicled flaps. For free flap transplantation, also no recipient vessels such as the circumflexa femoris lateralis vessels (previously used for the ALT flap), the circumflexa iliaca profunda vessels (used for the free parascapular flap), the circumflexa iliaca superficialis vessels (used for the pedicled groin flap) or the deep inferior epigastric vessels (used for the DIEP attempt) were available. Furthermore, the femoral vessels were too distant to the defect. Therefore AV loop was created from the femoral vessels using a great saphenous vein graft ${ }^{[14,15]}$. These kinds of AV loops have a relatively high thrombose rate compared to short subclavian loops for example ${ }^{[16]}$. Therefore we recommend a two-step procedure with first implantation of the AV loop and in a second procedure free flap transplantation. Using this protocol, flap loss due to an AV loop thromboses can be minimized. Patency was checked preoperatively using a Doppler ultrasound. For defect reconstruction we used a myocutaneous latissimus dorsi flap. This flap possesses a long vascular pedicle with adequate vessel diameter for microsurgical anastomoses to the great saphenous vein of the AV loop legs and it is known for its low flow resistance and therefore low complication rate when combined with an AV loop. Also, the latissimus dorsi flap provides enough muscle tissue for sealing the defect down to the trochanter major. Using the skin island a defect reconstruction without split skin grafting was possible.

Gawaziuk et al. ${ }^{[17]}$ also previously reported on a case series of free flap transfer after NF and was able to show no flap failures and a minimal complication rate. Beier et al. ${ }^{[18]}$ were also able to demonstrate a thoracic reconstruction using a bilateral free pre-expanded tensor fascia latae (TFL) flap in an 8-year-old child. Also Barbosa et al. ${ }^{[19]}$ showed a chest wall reconstruction using a free latissimus dorsi flap after NF. The special feature of the presented case are the multiple previously performed operations including local pedicled and random pattern flaps as well as a free flap, making any local flap impossible and further free flaps significantly more difficult. Therefore we had to perform a combined approach using AV loop and subsequent free latissimus dorsi transfer.

Tissue defects after NF often require an adequate defect reconstruction. Mostly this can be performed using split skin grafts or in regions with exposed structures such as bone or vessels, local or free flaps can achieve long-term stable results. Here we present a case of a NF in the trochanter major region after spondylodesis and SCS device implantation and multiple preoperations including local and free flaps. Therefore we performed a complex microsurgical reconstruction using AV loop and free latissimus dorsi transfer. This can be considered as the final stage of any reconstruction latter due to its high complexity.

\section{DECLARATIONS}

\section{Authors' contributions}

Manuscript preparation: Arkudas A, Regus S, Meyer A, Lang W, Schmitz M, Horch RE

Operative procedure: Meyer A, Lang W, Schmitz M

\section{Availability of data and materials}

Not applicable.

\section{Financial support and sponsorship}

None.

\section{Conflicts of interest}

All authors declared that there are no conflicts of interest.

\section{Ethical approval and consent to participate}

Not applicable. 


\section{Consent for publication}

Written informed consent for publication was obtained by the patient.

\section{Copyright}

(c) The Author(s) 2018.

\section{REFERENCES}

1. Kiat HJ, En Natalie YH, Fatimah L. Necrotizing fasciitis: how reliable are the cutaneous signs? J Emerg Trauma Shock 2017;10:205-10.

2. Stevens DL, Bryant AE. Necrotizing soft-tissue infections. N Engl J Med 2017;377:2253-65.

3. Horch RE, Hohenberger W, Weber K, Arkudas A, Beier JP. Myocutaneous transpelvic flaps do improve quality of life and help to reduce wound healing complications in patients receiving abdominoperineal resection in the real world. Int J Colorectal Dis 2016;31:1525-7.

4. Rother U, Lang W, Horch RE, Ludolph I, Meyer A, Gefeller O, Regus S. Pilot assessment of the angiosome concept by intra-operative fluorescence angiography after tibial bypass surgery. Eur J Vasc Endovasc Surg 2018;55:215-21.

5. Beier JP, Arkudas A, Lang W, Weyand M, Horch RE. Sternal osteomyelitis-surgical treatment concepts. Chirurg 2016;87:537-50.

6. Ludolph I, Lehnhardt M, Arkudas A, Kneser U, Pierer G, Harder Y, Horch RE. Plastic reconstructive microsurgery in the elderly patientconsensus statement of the German speaking working group for microsurgery of the peripheral nerves and vessels. Handchir Mikrochir Plast Chir 2018;50:118-25.

7. Meyer A, Goller K, Horch RE, Beier JP, Taeger CD, Arkudas A, Lang W. Results of combined vascular reconstruction and free flap transfer for limb salvage in patients with critical limb ischemia. J Vasc Surg 2015;61:1239-48.

8. Eweida AM, Lang W, Schmitz M, Horch RE. Salvage of a free radial forearm flap by creation of an arteriovenous fistula at the distal arterial pedicle. Microsurgery 2013;33:391-5.

9. Kuckelhaus M, Hirsch T, Lehnhardt M, Daigeler A. Necrotizing fasciitis of the upper and lower extremities. Chirurg 2017;88:353-66.

10. Sabaté Brescó M, Harris LG, Thompson K, Stanic B, Morgenstern M, O’Mahony L, Richards RG, Moriarty TF. Pathogenic mechanisms and host interactions in staphylococcus epidermidis device-related infection. Front Microbiol 2017;8:1401.

11. Steiner D, Hubertus A, Arkudas A, Taeger CD, Ludolph I, Boos AM, Schmitz M, Horch RE, Beier JP. Scalp reconstruction: a 10-year retrospective study. J Craniomaxillofac Surg 2017;45:319-24.

12. Rother U, Lang W, Horch RE, Ludolph I, Meyer A, Regus S. Microcirculation evaluated by intraoperative fluorescence angiography after tibial bypass surgery. Ann Vasc Surg 2017;40:190-7.

13. Cai A, Boos AM, Arkudas A, Horch RE. Management of extremely hard-to-heal extremity wounds with severe life-threatening complications. Int Wound J 2017;14:708-15.

14. Taeger CD, Horch RE, Arkudas A, Schmitz M, Stubinger A, Lang W, Meyer A, Seitz T, Weyand M, Beier JP. Combined free flaps with arteriovenous loops for reconstruction of extensive thoracic defects after sternal osteomyelitis. Microsurgery 2016;36:121-7.

15. Horch RE, Lang W, Arkudas A, Taeger C, Kneser U, Schmitz M, Beier JP. Nutrient free flaps with vascular bypasses for extremity salvage in patients with chronic limb ischemia. J Cardiovasc Surg (Torino) 2014;55:265-72.

16. Arkudas A, Horch RE, Regus S, Meyer A, Lang W, Schmitz M, Boos AM, Ludolph I, Beier JP. Retrospective cohort study of combined approach for trunk reconstruction using arteriovenous loops and free flaps. J Plast Reconstr Aesthet Surg 2018;71:394-401.

17. Gawaziuk JP, Liu T, Sigurdson L, Buchel E, Hayakawa TEJ, Shiga S, Logsetty S. Free tissue transfer for necrotizing fasciitis reconstruction: a case series. Burns 2017;43:1561-6.

18. Beier JP, Horch RE, Kneser U. Bilateral pre-expanded free TFL flaps for reconstruction of severe thoracic scar contractures in an 8-yearold girl. J Plast Reconstr Aesthet Surg 2013;66:1766-9.

19. Barbosa RF, Pinho CJ, Costa-Ferreira A, Cardoso A, Reis JC, Amarante JM. Microsurgical reconstruction of chest wall defect after necrotizing fasciitis. Microsurgery 2006;26:519-23. 